\title{
ARTICLE
}

\section{Gathering community perspectives to inform the design of autism-friendly music-making workshops for wellbeing}

\author{
Grace A. Thompson · Melissa Raine · Susan M. Hayward · Hannah Kilpatrick
}

\begin{abstract}
Many autistic people report experiencing social isolation, a recognized risk factor for poor psychological wellbeing. Promoting social inclusion is therefore a vital yet complex task. Community-based creative activities such as music groups can improve individuals' sense of social connection and reduce the experience of social isolation. However, limited literature is available that describes autistic people's perspectives about how to foster successful engagement in these creative and inclusive group opportunities. This project aims to gather perspectives from autistic individuals aged between 18 to 25 years to inform the design of autism-friendly musicmaking workshops for wellbeing. This co-design project involved a research team comprizing autistic and non-autistic academics, and an advisory group that included autistic young adults and autism advocates. Together, we designed an online survey and structured interview questions to gauge autistic people's preferences for engagement in group-based music activities. There were 30 responses to the online survey questions which collected demographic information, opinions about group music-based activities, and views about ways to best support access and participation in the local community. In addition, five structured interviews were conducted with survey participants who volunteered to provide in-depth follow-up responses. Survey data are presented descriptively, and interview data underwent inductive thematic analysis. Participants described being motivated to join music-making workshops offered in the community and proposed various ways to improve accessibility. The qualitative themes from the survey free text and interviews suggest that both environmental and social factors work together to create a sense of safety and inclusion. In particular, a welcoming atmosphere and acceptance of diversity were expected from the workshop facilitator and group members. These findings have important implications for the co-production of future music-making workshops for the wellbeing of autistic people.
\end{abstract}

Keywords: autism spectrum, young adults, music participation, co-design, creativity, wellbeing

\section{Introduction}

Social activities in the community that are accessible to a diverse range of people are scarce (Shiloh \& LaGasse, 2014). The number of autistic people in Australia is estimated to be somewhere between one in 70 people (Autism Spectrum Australia, 2018) and one in 150 (Australian Institute of Health and Welfare, 2017). Autism is hallmarked by challenges with social interaction, and often sensory sensitivities (American Psychiatric Association, 2013). The autistic community in Australia is substantial, yet a recent survey by a peak body for autistic people reported that the majority of the general public in Australia (84\%) perceive that discrimination against autistic people occurs (Jones, Akram, Murphy, Myers, \& Vickers, 2018). Perhaps unsurprisingly, $70 \%$ of the autistic participants surveyed in the same report felt socially 
isolated, while others indicated they had lost friends and jobs as a result of their condition and worried about how others would behave towards them. These relational concerns seem to spill over into their participation in Australian cultural life, with $54 \%$ of autistic people reporting their main reason for avoiding going out to venues was because they had nobody to go with (Jones et al., 2018). A study of 220 Australian autistic adults reported that the combination of environmental factors, such as noise levels, and social interaction challenges often create substantial anxiety and exhaustion leading to avoidance and isolation (Ee et al., 2019).

\section{Social Isolation and Mental Health}

The mental health of people living with disability is increasingly being recognized and reported, particularly within the Australian autistic adult population (Uljarević et al., 2019). Compared with the general population, as many as $60 \%$ of autistic people in Australia experience anxiety (Uljarević et al., 2019), and up to 49\% experience depression (Uljarević, Hedley, \& Cai, 2020; Uljarević et al., 2019). Both anxiety and depression increase suicide risk (De La Vega, Giner, \& Courtet, 2018; Hand, Benevides, \& Carretta, 2019), as highlighted by a large population-based study from Sweden reporting risk of death by suicide as seven times greater in autistic people compared with those in the general population (Hirvikoski et al., 2016).

Loneliness is frequently reported amongst autistic adults (Ee et al., 2019) and adolescents (Lasgaard, Nielsen, Eriksen, \& Goossens, 2010). Combined with a lack of perceived social support, loneliness also plays a role in suicide risk (Hedley, Uljarević, Wilmot, Richdale, \& Dissanayake, 2018). The majority (63\%) of autistic Australians aged under 21 years report experiencing difficulty fitting in socially (Australian Institute of Health and Welfare, 2017). Some autistic people camouflage their autistic traits in social settings in an attempt to "fit in" (Hull et al., 2017). Camouflaging can lead to feelings of shame and internalized stigma (Cage \& TroxellWhitman, 2019), and the effort and energy required to hide autistic traits can be detrimental to wellbeing (Hull et al., 2017). Therefore, finding ways to build inclusive social support networks appears to be fundamental to addressing mental wellbeing in an autistic population.

\section{First-Hand Perspectives on Social Isolation from Autistic People}

The neurodiversity paradigm (Singer, 1999, 2016) positions autism within the social model of disability, highlighting that society "tends to be physically, socially and emotionally inhospitable towards autistic people" (den Houting, 2019, p. 271). First-hand accounts from non-academic sources such as blogs and artworks provide deeply personal recounts of some of the social barriers experienced. Sarah Kurchak (2018) vividly describes the attitudinal barriers she faces, explaining "I've spent my whole life being told that non-autistic people are so brilliant and intuitive when it comes to social issues. Like many autistic people, though, I haven't always felt like I've seen much empathy, compassion, or understanding." Tim Chan's powerful poem I Can similarly comments on the impact of negative social attitudes:

In a non-comprehending world, in which I am an alien, a social misfit with no friends, I believe "I can't"...

I am going to see me as a person, guided by inner purpose, with the resources to fulfil my needs and dreams,

And I realize "I CAN" live the life I dream of. $($ Chan, 2015)1

\footnotetext{
${ }^{1}$ This excerpt of the full poem is reproduced here with permission.
} 
Within the social model of disability, the wellbeing of all citizens is a collective responsibility (Oliver, 1983, 2013). Disability theorists highlight this collective responsibility by noting a "double empathy problem" in society when autistic people are expected to understand nonautistic people, but non-autistic people do not seek to understand autistic ways of being (Milton, 2012). When autistic ways of being are perceived as abnormal, these negative impressions have been found to lead to social exclusion in Western countries (Sasson et al., 2017). Runswick-Cole (2014) reflects that while the neurodiversity movement has fought for the rights and recognition of autistic people, this position may intensify a binary sense of "us" and "them" which could unintentionally entrench beliefs about difference. In contrast, fostering knowledge and understanding of autism decreased stigma in college students from North America who participated in online training courses (Gillespie-Lynch et al., 2015) and briefing sessions (Curtis \& Mercado, 2004), suggesting that the "double empathy problem" can be improved through education and advocacy. Further, psychiatrists who call for greater acceptance of the broad spectrum of "autistic humanity" (Mottron, 2017, p. 823) emphasize that services for autistic people should focus on strengths rather than deficits, and foster individuals' access to social and cultural experiences.

\section{Music Participation, Social Engagement and Wellbeing}

Music forms a core part of the social life and cultural identity of many young adults (McFerran, 2020) including those on the autism spectrum (Allen, Hill, \& Heaton, 2009; Heaton, 2003). Participation in community music activities is associated with perceived positive wellbeing in Australian adults, particularly group-based activities where people feel socially connected to others (Krause, North, \& Davidson, 2019). Music therapy research also emphasizes the importance of shared moments of pleasure within creative group experiences for young people, along with validation of their identity from peers (McFerran, 2020). As such, music experiences have also been widely recognized as supporting the mental health and wellbeing of adolescents and young adults, both in the general population and people with disability (McFerran, 2020; Wilson \& MacDonald, 2019). Further, neuroscientists have documented music's influence on human emotions, finding that music-making can intensify social bonding and affiliation (Molnar-Szakacs et al., 2009; Peretz, 2019). Particularly, singing and active music-making in groups is more effective in promoting social cohesion than listening to music (Peretz, 2019).

This acknowledgement of the benefits gained from more active forms of music participation points to the important role that creativity plays in group social experiences and the potential flow-on benefits for enhanced wellbeing. Creativity in music making draws upon core features of human communication such as rhythmicity and predicable narrative form. These basic music potentials, or proto-musicality, are present in day-to-day acts of self-expression in all human beings from birth (Malloch, 2000; Malloch \& Trevarthen, 2018; Roginsky \& Elefant, 2020). As such, success in sharing aesthetically elaborated forms of self-expression is a benchmark for creativity that can be universally accessed since proto-musicality is a born potential that is present across the spectrum of neurodiversity (Roginsky \& Elefant, 2020). Opportunities for distributed creativity (Burnard \& Dragovic, 2015), as well as for dynamic engagement with culture (Wright \& Pascoe, 2015) may also promote connections between creativity and wellbeing. Group music-making is therefore a potentially powerful way to address the double-empathy issue and foster acceptance of autistic humanity, as it can provide an opportunity for these connections between creativity and wellbeing to be accessible to autistic participants.

The majority of music therapy research with autistic people has focused on developmental benefits for autistic children (Geretsegger, Elefant, Mössler \& Gold, 2014) such as supporting 
relational outcomes (Carpente, 2017; Thompson, 2017) and social communication skills (Kim, Wigram, \& Gold, 2008; Thompson, McFerran, \& Gold, 2013). Only a few studies have focused on evaluating the benefits of group music making for autistic adults. Preliminary findings from a Canadian pilot study with eight autistic adults found that participants reported less anxiety during a singing group compared to other activities (Young, 2020). Research exploring a group music skills program in the USA for 22 autistic adolescents and young adults found numerous self-reported social and wellbeing benefits including reduced anxiety, increased self-esteem and more positive attitudes toward peers (Hillier, Greher, Poto, \& Dougherty, 2012). However, while it is promising that autistic individuals report positive benefits from these music programs, the emphasis appears to be on boosting the capacities of the autistic person rather than addressing broader societal attitudes, which may reflect an ableist view of appropriate social norms (Campbell, 2009).

An alternative approach to improving access to community music events is the development of "sensory friendly concerts" (Shiloh \& LaGasse, 2014). These community events, often coordinated by music therapists and/or community arts organisations, seek to create an informal atmosphere and adapt the environment of the venue. Autistic people attending these events have described feeling more accepted by the community and more confident to express their autistic identity (Shiloh \& LaGasse, 2014). Organizers of sensory-friendly events typically consult and partner with autistic people to ensure access requirements are well understood; i.e., they employ a co-design approach.

\section{Co-Design and Participatory Research Approaches}

The Australian National Health and Medical Research Council (2016) acknowledges that consumer and community involvement in the design of research projects enhances the value of the project outcomes. Systematic reviews (Greenhalgh et al., 2019) and discussion papers (Locock \& Boaz, 2019) about co-design research suggest that no single approach or framework holds the key to success ${ }^{2}$. Greenhalgh at al. (2019) produced a taxonomy that consolidates the prolific and diverse approaches to co-design in the interests of clarifying their shared strengths. However, Locock and Boaz (2019) argue that in order to "avoid constructing people as vulnerable participants rather than partners with agency", co-design research must "move beyond tokenism and overcome the gap between language and practice" (Locock \& Boaz, 2019, p. 416 \& 418). Identifying and bridging gaps between thought processes and conceptual differences between researchers and community members is therefore central to successful co-design (Greenhalgh et al., 2019; Parsons, Fisher, \& Nalau, 2016). Research teams are encouraged to deeply consider their intentions and the purpose of engaging in co-design principles to determine which approach will be the best fit for the local context (Greenhalgh et al., 2019).

Co-design research involving autistic people highlights the importance of establishing trust, supporting diverse communication, and addressing power dynamics to ensure meaningful processes and outputs (Scott-Barrett, Cebula, \& Florian, 2019). Parsons et al. (2016) provide perspectives on co-design in Indigenous communities that emphasize some important advantages that might also be relevant when engaging autistic young adults in research. They report that indigenous participants drew attention to the colonialist ideals embedded in some of the concepts being utilized by researchers. When applying this notion to participants with lived experience, there may be real benefits to engaging with perspectives that challenge problematic assumptions in the research framework, such as the imposition of "neurotypical" (i.e., non-

${ }^{2}$ While the incorporation of first-person perspectives into co-design processes is generally considered to be important, how lived experience interacts with co-construction approaches is not currently well understood (Osborne et al., 2016). 
autistic) standards of socializing and communication. In response to these dynamic social justice principles, we embarked upon a co-design project by bringing together a research team comprizing autistic and non-autistic academics, and an advisory group that included autistic young adults and autism advocates.

\section{Purpose Statement}

Burnard and Dragovic (2015) observe that the context in which creative collaborations are undertaken has a powerful influence on their value to the participants. This contextual perspective underscores the importance of community consultation to ensure that the potential benefits to wellbeing are appropriate for the participant community.

This paper reports on our community consultation phase that aimed to gather the perspectives of autistic young adults living in Victoria, Australia. We sought to better understand whether music-making workshops would be a feasible way to address the previously reported social and wellbeing needs of the autistic community in the region where these workshops would later be offered. Information about how autistic young adults use music in their everyday life, what might motivate them to join a music-making workshop, and what they believe would improve access and engagement were gathered through a collaboratively designed online survey and interview guide.

\section{Method}

Co-Design Approach to Developing the Survey and Interview Questions

Our academic team includes autistic, disabled and non-autistic researchers with backgrounds in Psychology, Music Therapy, and Arts. We also invited young autistic adults to join an advisory group, since this age group would ultimately be invited to participate in the music workshops. The academic team created a first draft of the online survey questions to meet the research aims and then engaged with our three autistic advisors aged 18 to 24 years who reviewed the content, language, and formatting of survey questions. In addition, we took advice from the information manager of the autism peak body in Victoria, Australia, and a program coordinator of a community group for autistic young people. The wording and order of several survey questions were modified in an iterative way following this consultation period, with some questions removed and others added.

\section{Participants (Online Survey)}

Autistic people aged between 18 and 25 years living in the state of Victoria, Australia were invited to participate in an online survey advertized through local autism services and community groups via their social media pages, websites and eNewsletters. In keeping with our co-design aim, the survey was advertized as a call to "help us design autism-friendly music workshops". We limited the sample to the age group we intended to target in the subsequent study to increase the likelihood that the data will be relevant to phase 2 of this project. Similarly, survey participation was limited to people residing in the state where the music-making workshops would later be conducted. Thirty young people ( $M$ age in years=19.93; $S D=2.02$ ) responded to the 22 survey questions. Of these, 12 (40\%) identified as men, $12(40 \%)$ as women, and $6(20 \%)$ as other gender identities (transgender, gender-neutral, or gender queer). The majority of participants $(26 ; 87 \%)$ resided in a metropolitan area and had completed 12 or more years of education. All participants had an autism spectrum diagnosis, and many reported an additional diagnosis such as depression $(19 ; 63 \%)$, anxiety $(16 ; 53 \%)$, and attention deficit hyperactivity disorder (12; 40\%). See Table 1 for more detail. 
Participants (Follow-up Interviews)

At the end of the online survey, participants were asked to voluntarily participate in a follow-up interview by providing their contact details. Ten people $(33 \%)$ volunteered, and of these five (17\%) made appointments when invitations were sent via email. The age of these five interviewed participants ranged from 18 to 23 years ( $M$ age in years=20.0; $S D=2.0$ ), and included two people who identified as men, two who identified as non-binary, and one who identified as a woman (see Table 2 for more detail). Interviews were conducted on the phone or via the video conferencing platform Zoom. With permission, all interviews were video and audio recorded.

\section{Materials}

Survey

The survey consisted of 22 questions and included multiple choice, Likert scale items and free text options. The first 10 questions collected demographic information, questions 11 to 14 inquired about participants' use of music in their everyday life, and questions 15 to 22 invited participants to contribute their perspective on the design of the music workshops such as their preference for music activities, environmental considerations, access requirements, or any other considerations (see Appendix 1).

\section{Interview}

Five interview questions were constructed to align with the survey questions related to the design of the music workshops. While the interview questions were structured, we intended to seek deeper responses to these questions and gently prompt for more information (see Appendix 2). We emphasized to participants that their responses would directly impact the design of the music workshops planned in the second stage of the research.

\section{Ethics}

This project was approved by the Human Research Ethics Committee at The University of Melbourne (ID no. 1955735.1). Online survey participants provided their consent by clicking to commence the survey after reading the project information on the opening screen. All survey responses were anonymous. Interview participants were sent a Plain Language Statement via email and provided signed consent prior to the interview taking place. Transcribed interviews were anonymized, and each participant was assigned a code for reference.

\section{Survey Data}

The online survey was open during March and April 20203. All multiple choice and Likert scale questions are reported descriptively in the form of percentages and rankings.

${ }^{3}$ Data collection took place during the COVID-19 pandemic, where social restrictions were in place in this community. 
Table 1

Online survey participant data

\begin{tabular}{|c|c|c|}
\hline \multirow{2}{*}{$\begin{array}{l}\text { Characteristics } \\
\text { Age: years, M (SD) }\end{array}$} & \multicolumn{2}{|c|}{ Sample group $(N=30)$} \\
\hline & 19.93 & $(2.02)$ \\
\hline \multicolumn{3}{|l|}{ Gender } \\
\hline Male, $n(\%)$ & 12 & $(40)$ \\
\hline Female, $n(\%)$ & 12 & $(40)$ \\
\hline Transgender, $n(\%)$ & 1 & $(3.3)$ \\
\hline Gender neutral, $n(\%)$ & 2 & $(6.7)$ \\
\hline Gender queer, $n(\%)$ & 1 & (3.3) \\
\hline Other ${ }^{1}, n(\%)$ & 2 & $(6.6)$ \\
\hline \multicolumn{3}{|l|}{ Geographical location } \\
\hline Victoria: Melbourne metropolitan area, $n(\%)$ & 26 & $(86.7)$ \\
\hline Victoria: outside of metropolitan area, $n(\%)$ & 4 & $(13.3)$ \\
\hline \multicolumn{3}{|l|}{ Highest level of education } \\
\hline Bachelor degree or higher, $n(\%)$ & 3 & $(10.0)$ \\
\hline Diploma / Advanced Diploma, $n(\%)$ & 2 & $(6.7)$ \\
\hline Year 12 / Victorian Cert. Education / TAFE Cert. III or IV, $n(\%)$ & 15 & $(50.0)$ \\
\hline Year 10 / School Cert. / TAFE Cert. I or II, $n(\%)$ & 7 & $(23.3)$ \\
\hline$\leq$ Year $9, n(\%)$ & 3 & $(10.0)$ \\
\hline Autism spectrum diagnosis: yes, $n(\%)$ & 30 & $(100.0)$ \\
\hline \multicolumn{3}{|l|}{ Autism spectrum diagnosis confirmed by } \\
\hline Psychologist, $n(\%)$ & 12 & $(40.0)$ \\
\hline Paediatrician, $n(\%)$ & 6 & $(20.0)$ \\
\hline Paediatrician, Psychiatrist, $n(\%)$ & 2 & $(6.7)$ \\
\hline Psychiatrist, $n(\%)$ & 2 & $(6.7)$ \\
\hline Psychologist, Paediatrician, $n(\%)$ & 1 & (3.3) \\
\hline Psychologist, Paediatrician, Other health professional, $n(\%)$ & 1 & (3.3) \\
\hline Other health professional, $n(\%)$ & 2 & $(6.7)$ \\
\hline I don't remember who diagnosed me, $n(\%)$ & 4 & $(13.3)$ \\
\hline \multicolumn{3}{|l|}{ Age of autism spectrum diagnosis } \\
\hline Younger than 5 years old, $n(\%)$ & 6 & $(20.0)$ \\
\hline $6-10$ years old, $n(\%)$ & 9 & $(30.0)$ \\
\hline $11-15$ years old, $n(\%)$ & 10 & (33.3) \\
\hline $16-20$ years old, $n(\%)$ & 4 & $(13.3)$ \\
\hline 21 years and over, $n(\%)$ & 1 & (3.3) \\
\hline Other diagnosis in addition to autism spectrum: yes, $n(\%)$ & 19 & $(63.3)$ \\
\hline \multicolumn{3}{|l|}{ Other diagnosis details ${ }^{2}$} \\
\hline Depression & 19 & $(63.3)$ \\
\hline Anxiety & 16 & $(53.3)$ \\
\hline Attention deficit hyperactivity disorder (ADHD) & 12 & $(40.0)$ \\
\hline Post-traumatic stress disorder (PTSD) & 9 & $(30.0)$ \\
\hline Obsessive compulsive disorder (OCD) & 2 & $(6.7)$ \\
\hline Any eating disorder & 1 & (3.3) \\
\hline Other $^{3}$ & 3 & $(10.0)$ \\
\hline
\end{tabular}

${ }^{1}$ Other answers provided: queer, non-binary

${ }^{2}$ Multiple answers permitted

${ }^{3}$ Other answers provided: learning disorder, global developmental delay, auditory processing disorder 
Table 2

Interview participant data

\begin{tabular}{llll}
\hline Participant ID & Age (years) & Gender & Geographical location \\
\hline CM & 19 & non-binary & Victoria: Melbourne metropolitan area \\
IP & 19 & Male & Victoria: outside of metropolitan area \\
JB & 21 & Female & Victoria: Melbourne metropolitan area \\
LW & 18 & Male & Victoria: Melbourne metropolitan area \\
VSD & 23 & non-binary & Victoria: Melbourne metropolitan area \\
\hline
\end{tabular}

Note. Autism spectrum diagnosis confirmed by each participant.

\section{Free-Text and Interview Data}

The free-text survey questions and in-depth interview data underwent thematic analysis based on the approach described by Braun \& Clark (2006). The analysis sought to explicate themes and meanings within the data related to the research aim to deepen understanding about how autistic young adults might use music in their everyday life, what might motivate them to join a musicmaking workshop and what they believe would improve access and engagement.

Given that the survey participants were responding to structured questions, and the interview was also structured, the data were first sorted into overarching deductive topics. We then took an inductive approach to the analysis within each of these topics areas to best capture the authentic voices of the autistic participants and complement the descriptive data from the online survey. The qualitative analysis was an iterative process that broadly followed the following steps: 1) immersion in the data through the process of transcribing the interviews, reading and re-reading the data, and noting initial impressions of the data in memos; 2) segmenting the transcript statements and free-text survey answers into discrete concepts and compiling these into an Excel spreadsheet to sort the data into lines; 3) in-vivo coding of each line of data in order to reflect the expression of the participants as closely as possible; 4) sorting and grouping these in-vivo codes to identify potential descriptive themes; 5) reviewing and regrouping the descriptive themes through a reflexive process to identify possible relationships between themes; 6) a sample of the coding and themes were reviewed by a team member with lived experience of autism to cross-check the accuracy of the coding and labelling; and 7) refinement of the labels for the themes so that they succinctly capture the essence of the data.

\section{Results}

We begin by presenting the descriptive survey data, followed by the qualitative analysis of the survey free-text responses, and finally presenting the qualitative analysis of the interviews.

\section{Music Engagement in Everyday Life}

On average, these 30 respondents reported engaging in 6.13 hours of music listening per day. Most (93\%) survey respondents reported having played a musical instrument at some time in their life, while $40 \%$ reported they currently play a musical instrument well or at a high standard. The most popular instruments amongst these respondents were keyboard, guitar and drums (see Figure 1), but there was a large variety of instruments played by the participants across their life span. The majority of respondents also indicated that they like to sing to some degree (see Table 3).

\section{Preferences and the Design of the Music-Making Workshops}


These respondents' main reasons for wishing to attend a music workshop in the future focused on their enjoyment of music and their desire to continue to develop their music skills. However, social aspects were also considered important, with many respondents hoping to go out, make friends, meet new people, and try something new (see Figure 2).

Figure 1

Reported popularity of musical instruments within the sample (y-axis indicates frequency of response)

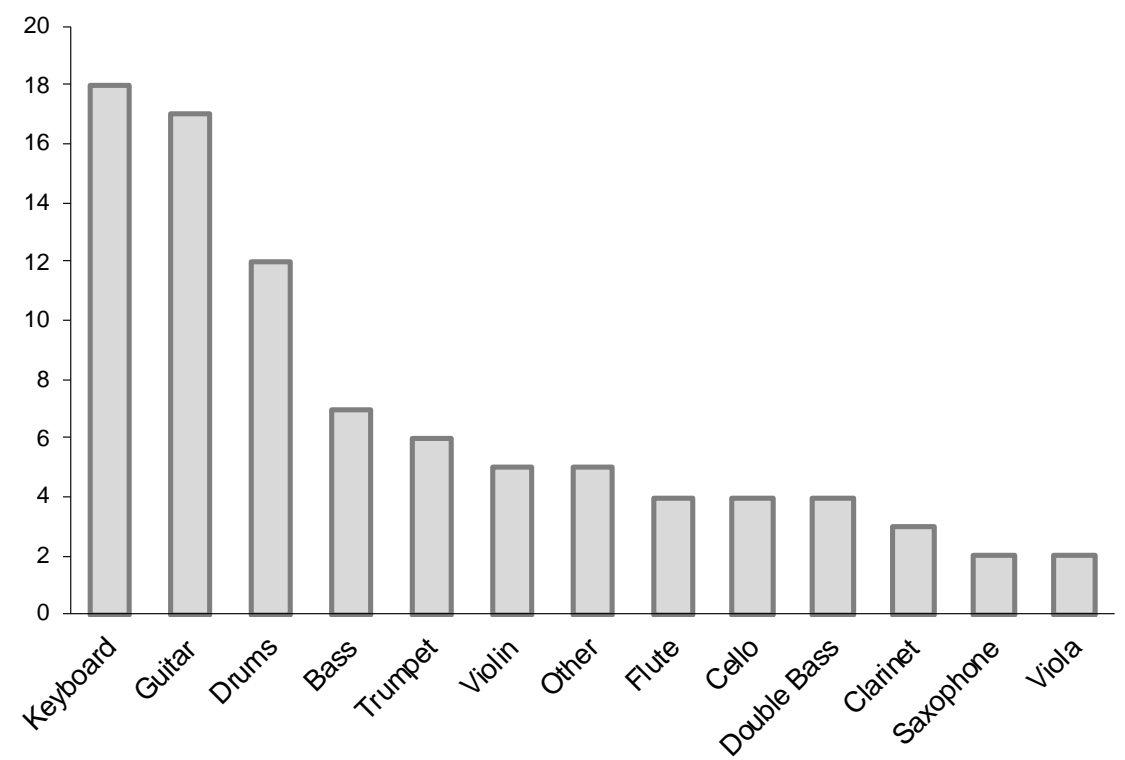

Note. The "Other" category consisted of ukelele, trombone, mandolin, oboe, bassoon

Table 3

Music engagement in everyday life

Music engagement type Sample group $(N=30)$

Hours of daily music listening, $M(S D)$

6.13

Music listening formats

Audio streaming ${ }^{1}, \%$

Video \& audio streaming 2 , \%

Personal music collection 3 , \%

Public broadcast ${ }^{4}, \%$

Has played at least one instrument at some time in their life, $n(\%) \quad 28$

Plays one instrument, $n(\%)$

Plays two-three instruments, $n(\%)$

Plays four or more instruments, $n(\%)$

Plays an instrument fairly well or at a high standard, $n(\%)$

9

12

Singing engagement

Does not like to sing at all, $n(\%)$

Likes to sing a little, $n(\%) \quad 10$

Likes to sing a lot, $n(\%)$

${ }^{1}$ includes Spotify, Apple Music, Soundcloud

2includes YouTube

3includes CDs, vinyl, iTunes

${ }^{4}$ includes listening to public radio stations 
Figure 2

Reported reason for attending the music workshop, by percentage

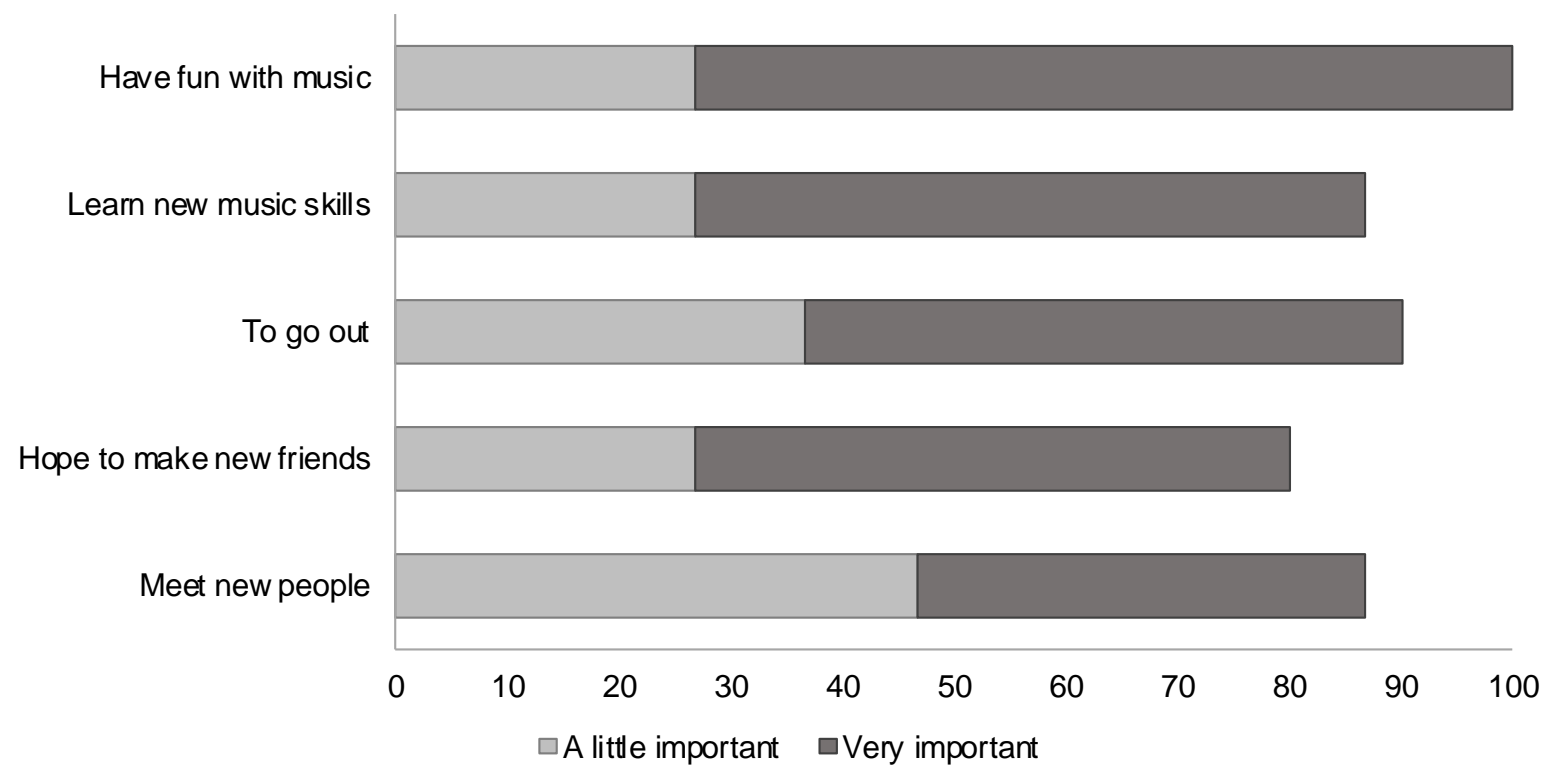

Preferred workshop activities

While there was strong interest in all suggestions for music activities offered in the survey, listening to music, playing instruments, and developing recording/production skills were most popular amongst this small sample. Of those ranked least preferred were other creative activities, song writing, performance, and singing (see Table 4, and Figure 3).

Table 4

Co-design of music workshops

\begin{tabular}{lrl}
\hline Co-design elements for music workshops & Sample group $(N=30)$ \\
\hline Workshop activities multiple choice options & & \\
Song writing & 9 & $(30.0)$ \\
$\quad$ Very interested, $n(\%)$ & 13 & $(43.3)$ \\
A little interested, $n(\%)$ & 8 & $(26.7)$ \\
$\quad$ Not interested, $n(\%)$ & & \\
Recording/production skills & 10 & $(33.3)$ \\
$\quad$ Very interested, $n(\%)$ & 15 & $(50.0)$ \\
$\quad$ A little interested, $n(\%)$ & 5 & $(16.7)$ \\
$\quad$ Not interested, $n(\%)$ & & \\
Listening to music & 19 & $(63.3)$ \\
$\quad$ Very interested, $n(\%)$ & 7 & $(23.3)$ \\
A little interested, $n(\%)$ & 4 & $(13.3)$ \\
$\quad$ Not interested, $n(\%)$ & & \\
Playing instruments & 15 & $(50.0)$ \\
$\quad$ Very interested, $n(\%)$ & 10 & $(33.3)$ \\
A little interested, $n(\%)$ & 4 & $(13.3)$ \\
$\quad$ Not interested, $n(\%)$ & & \\
Singing songs & 10 & $(33.3)$ \\
$\quad$ Very interested, $n(\%)$ & 12 & $(40.0)$ \\
A little interested, $n(\%)$ & &
\end{tabular}


Not interested, $n(\%)$

$8 \quad(26.7)$

Performance skills

Very interested, $n(\%)$

$10 \quad(33.3)$

A little interested, $n(\%)$

$11 \quad(36.7)$

Not interested, $n(\%)$

$8 \quad(26.7)$

Teamwork skills

Very interested, $n(\%)$

$4 \quad(13.3)$

A little interested, $n(\%)$

$18 \quad(60.0)$

Not interested, $n(\%)$

Other creative activities like story writing and/or

drawing

Very interested, $n(\%)$

$10 \quad(33.3)$

A little interested, $n(\%)$

$9 \quad(30.0)$

Not interested, $n(\%)$

$10 \quad(33.3)$

Access considerations multiple choice options

Number of people preferred in each workshop

It doesn't matter to me, $n$ (\%)

$9 \quad(30.0)$

Less than 5 people, $n(\%)$

$5 \quad(16.7)$

Between 6-10 people, $n(\%)$

$15 \quad(50.0)$

Between 11-15 people, $n(\%)$

1 (3.3)

Group members should all be on the autism spectrum

It doesn't matter to me, $n(\%)$

$20 \quad(66.7)$

Yes, I will feel more comfortable, $n(\%)$

3 (10)

No, I would like the group to be mixed, $n(\%)$

7 (23.3)

Factors that enable best participation in the workshops

Keep the noise level down

Not important, $n(\%)$

A little important, $n(\%)$

Very important, $n(\%)$

Provide verbal instructions

Not important, $n(\%)$

A little important, $n(\%)$

$16 \quad(53.3)$

Very important, $n(\%)$

11 (36.7)

Provide written instructions

Not important, $n(\%)$

$8 \quad(26.7)$

A little important, $n(\%)$

$11 \quad(36.7)$

Very important, $n(\%)$

Provide a quiet/private space to take a break

Not important, $n(\%)$

$3(10.0)$

A little important, $n(\%)$

8 (26.7)

Very important, $n(\%)$

Provide snacks

Not important, $n(\%)$

$\begin{array}{ll}9 & (30.0)\end{array}$

A little important, $n(\%)$

$6 \quad(20.0)$

Very important, $n(\%)$

Include free time to get to know other people

Not important, $n(\%)$

A little important, $n(\%)$

Very important, $n(\%)$

13 (43.3) 


\section{Access considerations to enable participation}

Generally, these respondents preferred smaller groups for the music workshops, with 6 to 10 people being the most popular group size, followed by groups of fewer than five people. When asked if the group should be exclusively offered to people on the autism spectrum, most respondents in this small sample indicated that it did not matter, while almost a quarter of respondents would prefer to interact with a mixed group of people. It seems that these participants were motivated to come to the music workshops in order to make new friends and meet new people (see Figure 3).

Figure 3

Workshop activities participants were most interested in, by percentage

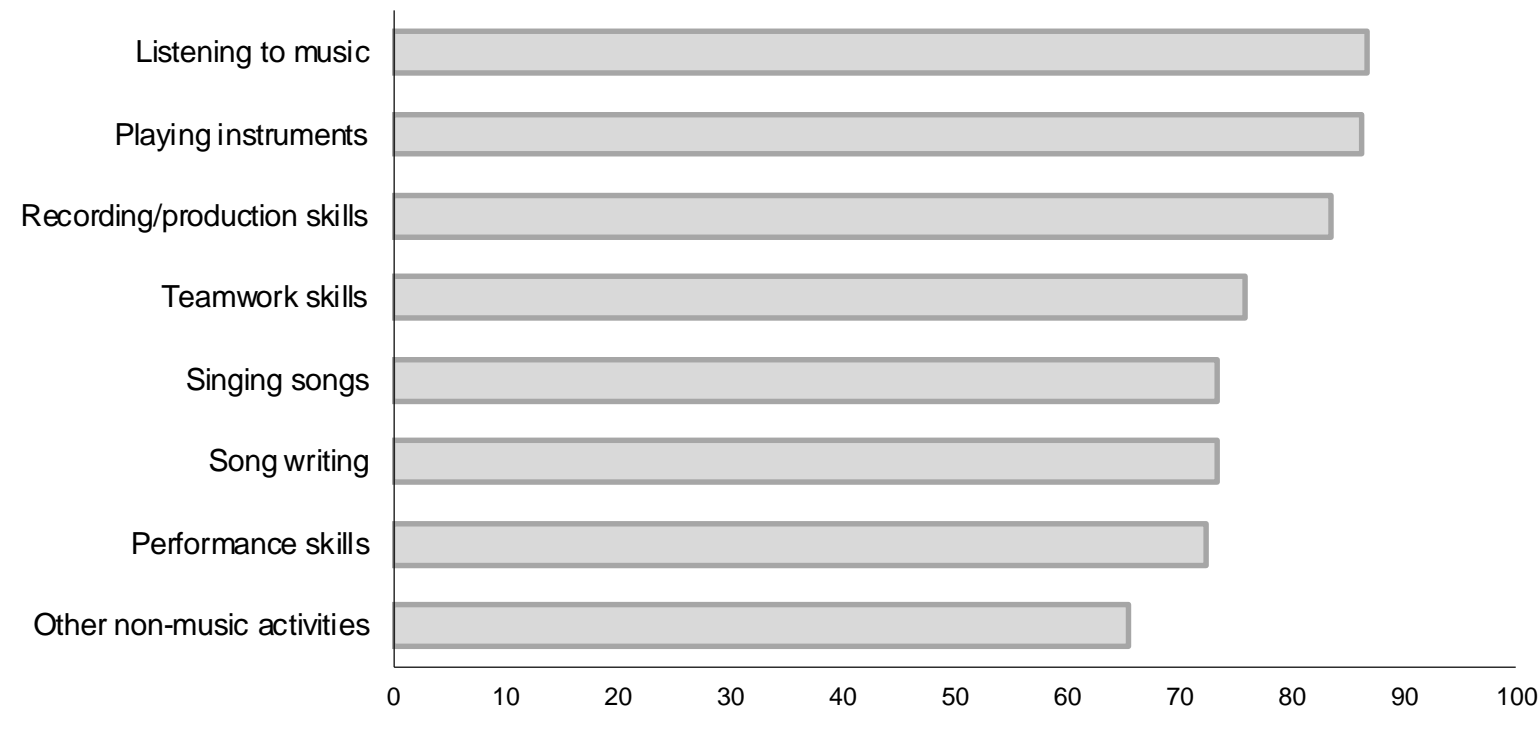

In terms of environmental factors, these participants indicated that access to a quiet or private space would allow them to take a break from workshop activities. Providing snacks at the workshop was also considered important for participation, as well as free time to get to know other people in the group. In this small sample, that reported being highly engaged with music, keeping noise levels down was only considered "a little important" (see Figure 4). 
Figure 4

Factors that were considered important to enable participation, by percentage

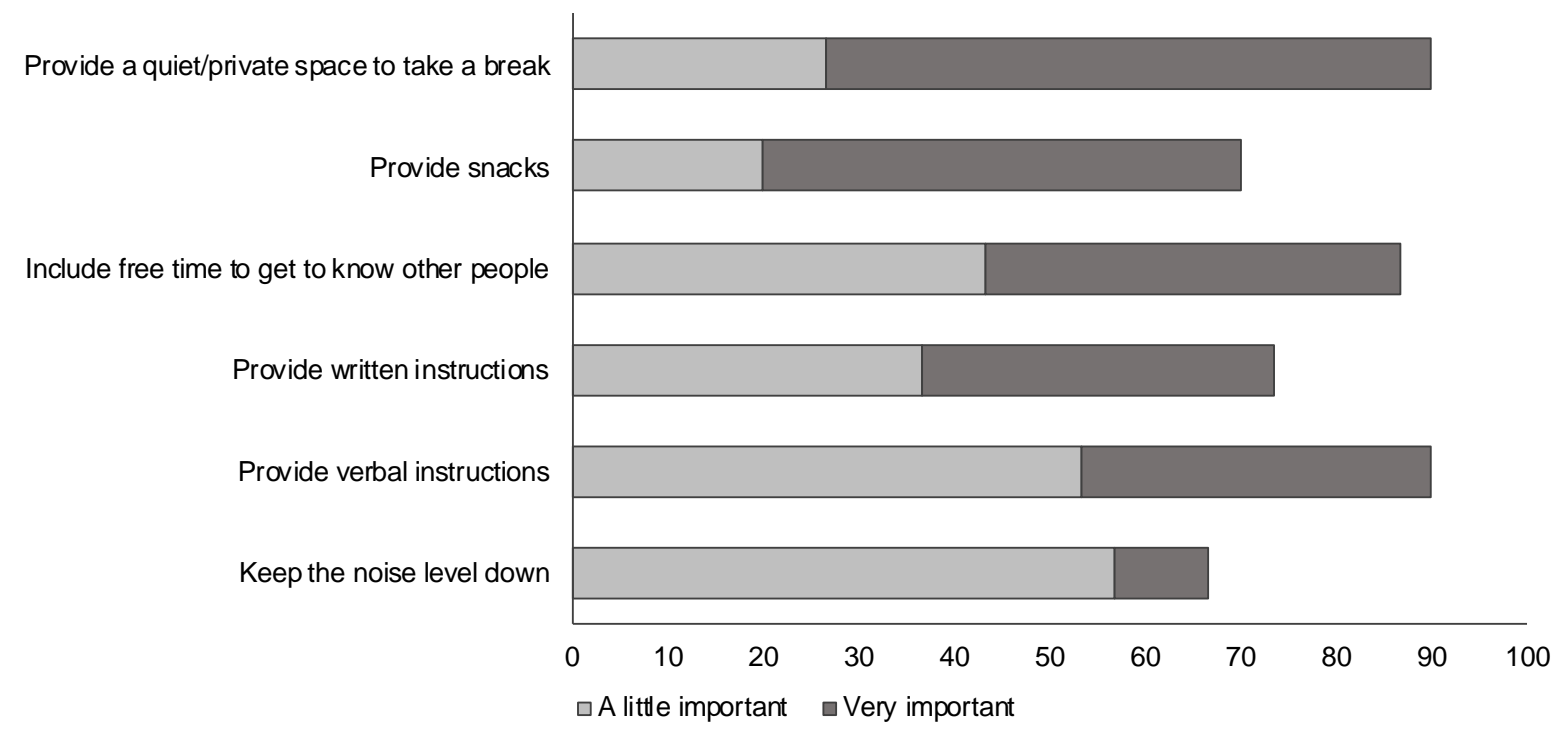

Qualitative Themes from the Survey Responses

Eighteen of the 30 respondents $(60 \%)$ provided answers to some or all the five free-text questions in the online survey. Most responses concerning the main reason for attending the workshop focused on developing music skills and music knowledge. However, one respondent replied they would come along to "have a purpose" (participant no. 11). In the free text answers, there were mixed opinions about whether everyone in the group should be autistic. Some people wanted the group to be open in order to meet new and different people, while others wanted a supportive space free from the judgement of non-autistic people. Participant 22 stated, "As an autistic adult I'm often not understood and regularly judged by neurotypical people." In contrast, participant 24 explained:

I would like to meet more people on the spectrum as I'm newly diagnosed, but I don't want to limit myself to just making friends with people who are autistic. Sometimes it's good to make friends with people who don't have the same barriers than me [sic] so they can support me through social issues I have.

In terms of support during the workshops, some respondents emphasized the importance of creating an encouraging atmosphere with the right balance between structure and flexibility. Participant 10 described wanting

... [to] have a structure set in place but be prepared that some people will flow off it and find something they like and not want to move on from (for example if they just realized they can play certain songs by ear on piano they'll possibly want to explore that as much as possible while they have the chance and enjoy that one thing instead of moving on).

Two people asked for accommodation of sensory sensitivities, such as availability of headphones to manage auditory sensitivity, and natural light in the room. Participant 21 emphasized the importance of respect for participants, stating "Do NOT treat us like we're mentally handicapped" [emphasis copied from participant's text response]. Five people offered direct 
advice to the future workshop facilitators. Three of the five considered it important for the facilitator to have a deep knowledge of autism, and one person considered that their experience should include personal knowledge rather than simply professional experience (see Table 5).

Table 5

Qualitative themes from free-text survey questions

\begin{tabular}{|c|c|c|}
\hline $\begin{array}{l}\text { Survey question } \\
\text { (no. of participants } \\
\text { responding) }\end{array}$ & Theme & $\begin{array}{l}\text { No. of } \\
\text { participants }\end{array}$ \\
\hline \multirow{5}{*}{$\begin{array}{l}\text { What would be your main } \\
\text { reason to come to the music } \\
\text { workshops? (8) }\end{array}$} & Offer structured music learning & 2 \\
\hline & Opportunities for band work & 2 \\
\hline & $\begin{array}{l}\text { Learning strategies to use music for therapeutic } \\
\text { application }\end{array}$ & 1 \\
\hline & Expand the activities beyond music & 2 \\
\hline & To have a purpose & 1 \\
\hline \multirow{4}{*}{$\begin{array}{l}\text { Should everyone in the } \\
\text { group be on the autism } \\
\text { spectrum (autistic)? Why or } \\
\text { why not? (12) }\end{array}$} & $\begin{array}{l}\text { Open group is beneficial to meet a range of } \\
\text { people }\end{array}$ & 7 \\
\hline & $\begin{array}{l}\text { Open group but people should have an } \\
\text { understanding of autism }\end{array}$ & 1 \\
\hline & $\begin{array}{l}\text { Closed group to offer support to each other and } \\
\text { not be judged }\end{array}$ & 3 \\
\hline & $\begin{array}{l}\text { Quality music-making experiences are more } \\
\text { important than diagnosis }\end{array}$ & 1 \\
\hline \multirow{7}{*}{$\begin{array}{l}\text { Is there anything else that } \\
\text { we should do to support } \\
\text { you? (11) }\end{array}$} & Create groups with similar levels of music skills & 1 \\
\hline & Cater for dietary needs & 1 \\
\hline & Provide resources to take home & 1 \\
\hline & $\begin{array}{l}\text { Workshop structure should be flexible and } \\
\text { encouraging }\end{array}$ & 5 \\
\hline & Create space to socialize & 1 \\
\hline & Accommodate sensory sensitivities & 2 \\
\hline & Provide individual music instruction if needed & 1 \\
\hline \multirow{3}{*}{$\begin{array}{l}\text { Do you have any more } \\
\text { advice for our workshop } \\
\text { leaders? (5) }\end{array}$} & $\begin{array}{l}\text { Create different workshops based on music } \\
\text { ability }\end{array}$ & 1 \\
\hline & Deep knowledge of autism is preferred & 3 \\
\hline & Create a friendly atmosphere & 1 \\
\hline
\end{tabular}

Note. 18/30 respondents provided answers to some or all of the 5 free-text questions in the online survey.

\section{Qualitative Themes from the Interviews}

The structured interviews with five participants ranged from 20 to 40 minutes in duration. The main themes forming the qualitative analysis are described below, with the codes related to each theme provided in Table 6. To distinguish the survey free-text responses from the interview quotes, each interview participant has been given a code based on their initials. These codes also serve to de-identify the participants.

\section{Music in everyday life}

Three of the five participants described themselves as active musicians, while four described how they regularly use music for recreation and their own wellbeing. Using music to shift their mood, 
manage feelings of frustration and reduce stress (i.e., regulate their emotions) were common experiences amongst these participants. For example, participant VSD notes:

I also like improvise songs quite a lot. And so and then that then [sic] leads to song writing as well, um, which is quite a quite a good way to get rid of frustrations [voice rises] or even just like talk about thoughts on my mind and stuff like that.

Similarly, participant JB explains

... if I do housework or I'm doing some work or study or something. I might listen to it for some background music... And yeah it can change my mood, like...I guess it depends on the style of music I'm listening to or...it can just, if I'm studying for something it can make me feel a bit more calmer [sic] and concentrate better.

Motivation to attend music-making workshops in the future

All five participants described their desire to meet new people with similar interests. Within this theme, participants wanted to be accepted and meet friendly people. Some participants were also interested to meet other autistic musicians and share experiences of their use of music, with participant IP describing "I'd be really interested in getting to know musicians that, you know, share similar things that have been diagnosed with and...um, get to know what music does for them and all that sort of stuff as well."

\section{Improving access to participate}

Participants offered various suggestions for what would make it easier for them to participate in music workshops, ranging from environmental issues related to the venue, to the social atmosphere of the group. The importance of a welcoming atmosphere was emphasized by four participants who expressed their hope that the workshop would be a safe and non-judgemental space. When prompted to explain what would make the group a socially safe space, participant LW explained "Um, where you can speak out without like being judged and...things like that." Participant JB explained that he would feel accepted and included by "people being interested in me, asking me questions, and um, us like going out and doing things and making, um, like a true friendship group. Yeah."

The physical environment of the venue was also important to two people. They both commented on the need for air and natural lighting, and there was a sense that these environmental factors are also part of creating a feeling of safety and security. Participant CM explains that they need

... [to be] able to breathe in rooms. I say that because one of the previous things that I did a few years back, ah, it's a sensory room, it had no aircon or vents, and was not near a window. So it looks like it looked like they converted an old broom closet. I couldn't breathe I wanted out.

In addition, four of the five interview participants commented on the importance of having a separate space to take a break away from the main group at any time. This separate space was described as important for participants to manage feelings of being overwhelmed, provide a private place to "stim" (self-stimulatory behavior), or engage in other self-regulating and calming activities if needed. Participant VSD explained this need in detail as follows: 
Having an additional room for anyone who needs to... a private room for anyone to...and if it was made to be as comfortable as possible... Because like I sometimes get, um, like stimming attacks, and you don't want people around for that [laughs] sometimes and so a lot of time your options are run to the bathroom or have everyone witness what's going on. And perhaps having like a dedicated room where you can just go and do that it would be really good.

Advice for the music workshop facilitator

All five participants emphasized the importance of the facilitator being inclusive and considerate of differences. They described the need for the facilitator to be friendly, but also give clear social cues. Some participants stated that they were thinking about the needs of other autistic people they know, as well as themselves. The interviewees emphasized the caring and supportive attitude they expect the facilitator to have, with participant IP describing these qualities in detail:

Just be aware of um...If someone is not feeling 100\% about, you know, what's going on then...just, walk up...it's okay to just walk up and let them know, "hey, if you need a break just go and have a break." When it comes to autistic people, I think a lot of times they're just...don't know what to say about that sort of stuff sometimes...they might not communicate that sort of thing.

The importance of the facilitator giving clear social cues that are congruent with their feelings was emphasized by one participant, VSD, who described how this helps them to feel safe and confident:

Um, ... [the facilitator should] smile. That's probably a weird thing to say...I try to...I tend to read people too much to kind of gauge how they're like feeling and whether they're going to be an approachable person so if they look as friendly as possible, that's probably gonna [sic] start everything off pretty well.

Table 6

Qualitative themes from in-depth structured interviews

\begin{tabular}{lll}
\hline Theme (no. of participants) & Code & \\
\hline Question &
\end{tabular}

Tell us a little about how you use music in your life?

\begin{tabular}{|c|c|}
\hline Currently an active musician $(3 / 5)$ & Play guitar in a band \\
\hline & Committed to improve music skills \\
\hline & Write songs for a band \\
\hline & Have participated in song writing workshops \\
\hline & Love playing drums \\
\hline & Love music and have been playing from a young age \\
\hline & Love to sing in different styles \\
\hline & Have lots of music skills but self-conscious in front of others \\
\hline Previously played an instrument (2/5) & Used to perform in a band \\
\hline & Used to learn keyboard \\
\hline Engages with music for recreation $(4 / 5)$ & Extensive music listening \\
\hline & Listening to music \\
\hline & Sing in the shower \\
\hline & Go to gigs and live shows occasionally \\
\hline
\end{tabular}


Uses music for wellbeing (4/5)
Play guitar to calm down

Background music to intentionally regulate my mood

Listening to music makes me feel happy

Playing instruments is an important stimming activity that helps me when I'm frustrated

Playing instruments is also a way to deal with frustration

Song writing is a way to express frustrations and emotions

Listening to music to reduce stress and stay focused

Question

Tell us more about music activities you are interested in, and why?

Build on existing music skills (2/5) Continued passion for song writing in a band

Constructive feedback to improve music skills

Learn new music skills (3/5)

Learn music recording skills

Start learning drums or guitar

Willing to give singing a go

Learn music skills

Listen to music and talk with others

Listening to music and talking about favorite music $(2 / 5)$

Question 3:

What is your main reason to come to the music workshops? Why is this most important to you?

Learn new music skills (3/5)

Learn more music skills

To try something new with music

Meet new people with similar interests

Meet new people

Meet other musicians with similar interests

Meet new people and be accepted

Be with friendly people

Share experiences with other autistic musicians $(2 / 5)$

Meet other autistic musicians \& share experiences

Have an opportunity to perform music

Be part of a supportive community of autistic musicians

Perform music to an audience

Motivate me to use my music skills more actively with others

Question

4 :

What makes it easier for you to participate in group music activities?

Provide a space to take a break (4/5) Provide space to take a break if the group becomes too much. Space to address overstimulation

Space to take a break from the noise

Space to take a break if I need to stim

Break out rooms to allow small groups to focus on an area of interest

Venue needs to have air and natural Air and natural light are important to create a safe space light $(2 / 5)$

Give information about the room and the group before the workshops start

Prefer natural light in the room

Natural air and comfortable temperature are important to consider

Group size should not be too big (4/5) Too many people can be overstimulating

Group size between 5-15 people

Group size between 10-20 people 


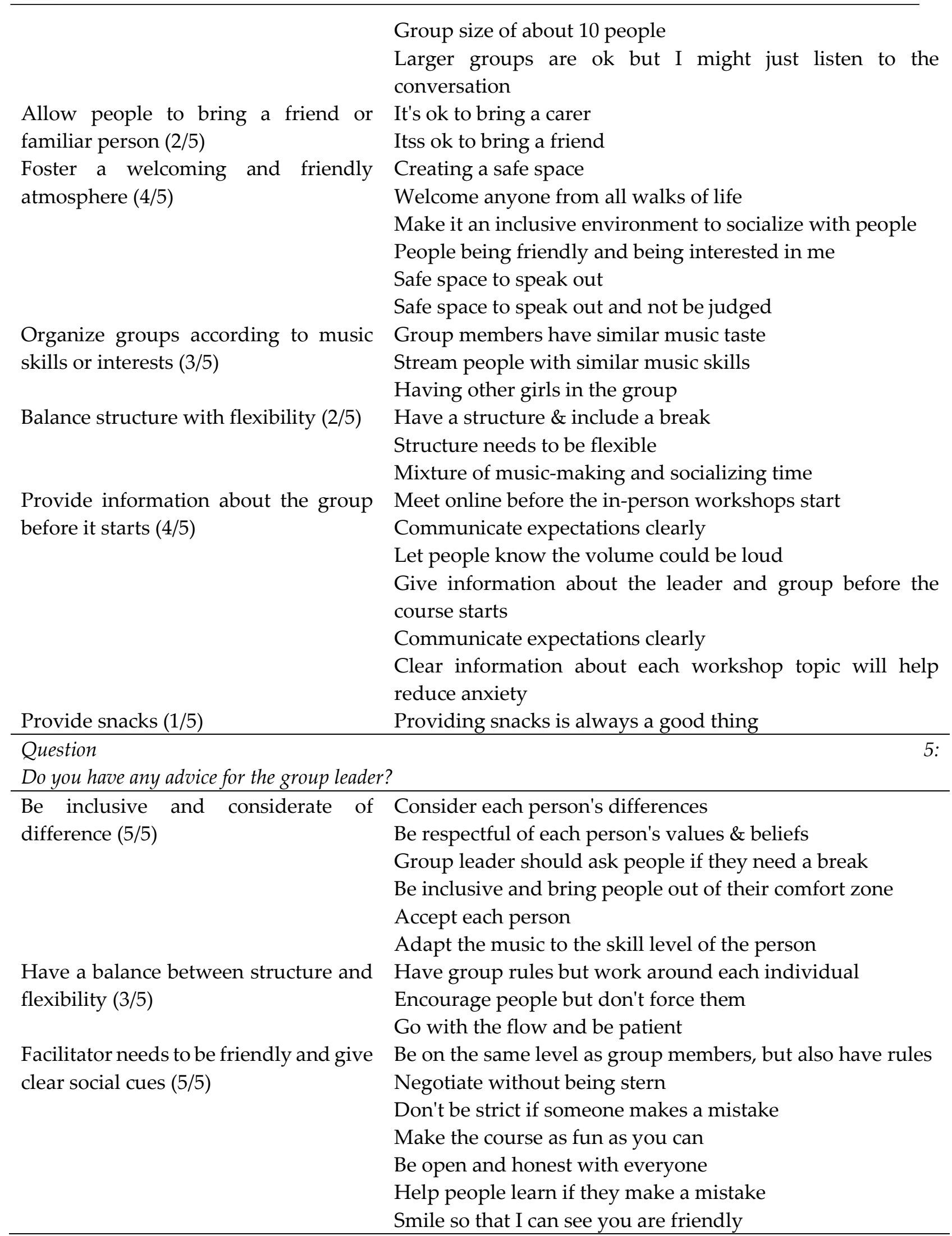

\section{Discussion}

Given the elevated levels of poor psychological health outcomes for some autistic people, as well as their self-reported lack of social support (Uljarević et al., 2020), this project aimed to gather perspectives from autistic young adults to inform the design of future autism-friendly 
community music workshops which intend to improve wellbeing and increase social connection. We sought to better understand how individuals from the intended participant community use music in their everyday life, what might motivate them to join a music-making workshop, and what they believe would improve access and engagement.

The invitation to complete a survey to design autism-friendly music workshops seemed to attract the interest of autistic people who are already highly engaged with music. The average of 6.13 hours of music listening per day reported in this small sample is similar to reports of the general population of young people's music listening habits. A large survey of teenagers in the UK found that they listened to 2.45 hours of music per day on average (North, Hargreaves, \& O'Neill, 2000); however, a study from the USA reported up to 7.5 hours of music listening per day when teenagers were multi-tasking with music playing in the background (Rideout, Foehr, \& Roberts, 2010). While we did not ask our respondents to clarify whether music listening was used to accompany other activities per se, the results here suggest that autistic young people listen to music to a similar degree to the general adolescent population.

Within the survey sample, nearly all respondents reported having played an instrument at some time in their life, with $40 \%$ still playing their instrument to a self-reported "high standard". This high level of engagement with music may have been a reason that the majority considered keeping noise levels down in the groups was only "a little important" rather than "very important". However, this assumption requires further investigation. Even though most respondents in this small sample were motivated to continue to develop their music skills in future workshops, expanding their social network was also widely described as a reason to participate.

However, there were contrasting opinions about whether the workshops should be exclusively for autistic people, or inclusive of non-autistic people. The free-text and interview data revealed that some participants were worried about being judged by non-autistic people or being misunderstood. Others particularly wanted to meet other autistic musicians to understand more about how they used music in their life and share common experiences with music. Those who were comfortable with being part of an inclusive group emphasized that members should have a good understanding of autism, be accepting, friendly, and share common interests in music. These concerns link to the literature highlighting that attitudes of non-autistic people are likely to be barriers to social inclusion (den Houting, 2019; Office of Civilian Human Resources, 2016). The perspectives of autistic participants in this small sample further support the view of a "double empathy problem" in society more generally (Milton, 2012) and the need for autismfriendly community activities.

Similar sentiments are noted in the advice that the survey and interview participants offered to the future workshop facilitators. There was an emphasis on respect, understanding of difference, acceptance and accessibility. The responses gathered from this sample highlighted the need for structure but also for flexibility so that group members would be encouraged to try new things yet have autonomy in decision-making and level of engagement. The quality of facilitation in group music experiences has been noted in previous research evaluating the social impact of music programs for people with disability. Wilson and MacDonald's (2019) qualitative findings suggest that workshop leaders with an empathic and inclusive attitude facilitated feelings of welcoming, involvement, and security in disabled participants. Their findings also described how tailoring the music activities to the interests and potential of the participants was key to their sustained engagement in the workshops (Wilson \& MacDonald, 2019).

While this survey has a small sample, the responses highlighted various factors consistent with social-communication challenges, as well as common sensory sensitivities associated with 
autism (American Psychiatric Association, 2013). Regardless of the small importance attributed to noise levels, participants reported that accessibility would be improved with clear written and verbal information as well as provision of a break-out space to help avoid overwhelming situations. Compared to the survey data, the interview responses highlight slightly different considerations relating to the environment of the music workshops. Two people noted the importance of air and natural light, which could be considered important to promote feelings of security and safety. These perspectives underline the importance of regularly checking accessibility with each participant to ensure that community-based activities will indeed be autism-friendly.

When asked in the in-depth interviews to describe how they use music in their everyday life, most of the five participants shared the various ways that their music use is linked to improving wellbeing. These participants played their instruments to regulate their emotions, for example, as a "stimming" activity to self-soothe. Participants who composed music and songs further commented on emotional regulation, describing how their creativity was an outlet for expressing emotions and frustrations. It is noted that autistic individuals often have difficulty with emotional regulation, which is linked to mood disorders such as anxiety and depression (Morie, Jackson, Potenza, \& Dritschel, 2019; Weiss, Riosa, Mazefsky, \& Beaumont, 2017). Both anxiety and depression were elevated in the current sample (see Table 1).

These respondents seemed less informed about the potential for music-making to create opportunity for social inclusion beyond sharing an interest with others. Given that the survey responses and interview data indicate that participants are interested in increasing their social network, there may be a need to raise awareness of the potential of music-making in groups to boost social bonding and affiliation (Krause et al., 2019). Given that research findings from the general adolescent population suggest that most young people engage daily in several hours of music listening (North et al., 2000; Rideout et al., 2010), experience pleasure in music engagement, and a sense of connection to peers (McFerran, 2020), we were surprised the sample almost exclusively included respondents who had previously played a musical instrument. We had expected that there would be more variety in the respondents' characteristics, including people who simply enjoyed music as well as those who had experience playing instruments. Given the benefits of music engagement for wellbeing are not limited to those who have experience playing instruments (Krause et al., 2019; Peretz, 2019), we consider that participant characteristics are important to consider in the subsequent co-design stage of the project. If music-making workshops are likely to only attract autistic musicians rather than music lovers more generally, this will shift the focus of the workshops towards activities that require music skills and knowledge. In fact, several participants commented that the workshops should be organized according to music skill level.

It is well recognized that participants iteratively shape the services they receive, which makes co-production intrinsic to the delivery of responsive and meaningful services - whether this occurs consciously or not (Osborne, Radnor \& Strokosch, 2016). Rather than utilizing the present survey responses and interviews to determine prescribed qualities for future music workshops, the data are understood to reveal that autistic individuals should be recognized as research collaborators with agency and respected accordingly (Locock \& Boaz, 2019). Our own diverse research team considers that the most compelling data relate to the young people's expectations of the workshop facilitators: that they should be friendly, have a deep understanding of autism, be respectful of each person's values and beliefs, and accept each group member. The challenge, however, of creating an inclusive culture should not depend on the group facilitator alone. Good facilitation therefore may be more about galvanizing each group member's sense of agency and, 
through a participatory approach, generating further understandings about social connection that challenge the expectations of non-autistic people.

\section{Limitations}

The survey and interview data are limited to the views of autistic young adults in the State of Victoria, Australia. Since this was the first phase of a larger co-design project, we sought perspectives from the community where the music workshops would ultimately take place. However, this approach also means that the representation of the sample itself is limited. The potential pool of respondents could not be determined due to recruitment taking place via social media platforms and eNewsletters where snowballing was possible. Additionally, the survey tool was open during March and April 2020, a time when there were social restrictions in Victoria, Australia due to the COVID-19 global pandemic.

Participant recruitment unintentionally attracted autistic people with considerable preexisting musical training. Their perspectives may therefore differ from autistic people who are music lovers, rather than musicians. For the qualitative analysis, our autistic team members reviewed the final themes from the perspective of their own lived experience. However, this should not imply that they were able to represent every unique autistic perspective. Future codesign projects should consider ways to ethically conduct member checking of qualitative themes in a collaborative way.

Additionally, while our diverse team developed the survey in collaboration with three autistic young adults, an autism community group, and a representative from an autism advocacy peak body, survey participation can bias the sample toward individuals who prefer to communicate in writing or verbally. Therefore, individuals with different communication and expression needs within the autistic community may not be represented. This limitation is acknowledged as a common challenge in co-design projects with neurodivergent people (Tisdall, 2012).

\section{Conclusion}

Previous research has shown that community music-making groups may expand participants' social networks, yet there may be conditions which limit accessibility for autistic people. While the sample size informing this report is modest, the findings suggest that some autistic people, particularly those who have a pre-existing interest in music, may be motivated to join autismfriendly community music workshops. Along with various practical suggestions for improving accessibility, such as providing break-out spaces, selecting venues with natural light and air, and providing instructions in multiple formats, many of these participants also emphasized relational factors that would lead them to feel welcomed and accepted. These relational factors included participants' expectations that the group facilitator should have a deep understanding of autism and be able to foster friendly and respectful interactions between group members. The perspectives of these participants regarding the importance of providing a safe and nonjudgmental space warrants consideration in the design of future intervention studies. By articulating the need for attention to these personally significant environmental and socioemotional factors, these participants invite researchers to deeply consider the elements that can either support or hinder participation in music-making activities for wellbeing. Health promotion programs are likely to benefit from taking a co-design approach to designing activities and evaluating outcomes for the participant community. 


\section{Acknowledgements}

This project received funding from the Creativity and Wellbeing Hallmark Research Initiative (CAWRI) at the University of Melbourne. We wish to acknowledge our lived experience advisory group members: Mitchell Gee, Matilda Gardner \& Daniel Munter; and our community consultants Melinda Spencer (program coordinator, "Different Journeys" autism social support group), Michael Davern (treasurer, "Different Journeys" autism social support group), and Elena Ashley (Manager, Information \& Services, AMAZE, peak body for the Autism community in Victoria, Australia).

\section{Conflict of interest statement}

The authors report no conflicts of interest.

\section{Authors}

Grace A. Thompson

The University of Melbourne

Melissa Raine

The University of Melbourne

graceat@unimelb.edu.au

Susan M. Hayward

Deakin University

Hannah Kilpatrick

The University of Melbourne

\section{Publishing Timeline}

Received 2 September August 2020

Accepted 26 November 2020

Published 17 December 2020

\section{Appendices}

\section{Appendix 1}

Online survey questions

\begin{tabular}{|c|c|c|}
\hline $\begin{array}{l}\text { Question } \\
\text { number }\end{array}$ & Data theme & Survey question \\
\hline 1 & Demographics & My age is... \\
\hline 2 & & I live in... \\
\hline 3 & & My sex at birth was... \\
\hline 4 & & I identify as being... (gender options provided) \\
\hline 5 & & My highest level of completed education is... (multiple choice) \\
\hline 6 & & $\begin{array}{l}\text { Have you been formally diagnosed with either Autism, Autism } \\
\text { Spectrum Disorder (ASD), Asperger's Disorder (AD), Asperger's } \\
\text { Syndrome (AS), or Pervasive Developmental Disorder-Not Otherwise } \\
\text { Specified (PDD-NOS)... (multiple choice) }\end{array}$ \\
\hline 7 & & $\begin{array}{l}\text { The professional that diagnosed me was (select all that apply)... } \\
\text { (multiple choice) }\end{array}$ \\
\hline 8 & & $\begin{array}{l}\text { To the best of my knowledge, I was diagnosed at age... (multiple } \\
\text { choice) }\end{array}$ \\
\hline
\end{tabular}




\begin{tabular}{|c|c|c|}
\hline 9 & & $\begin{array}{l}\text { Apart from Autism, ASD, AD, AS/PDD-NOS, have you been } \\
\text { diagnosed with another condition? (yes/no) }\end{array}$ \\
\hline 10 & & If yes, select all conditions that apply... (multiple choice) \\
\hline 11 & $\begin{array}{l}\text { Music } \\
\text { engagement }\end{array}$ & $\begin{array}{l}\text { On a usual day, how many hours of music do you listen to? (slider to } \\
\text { select). }\end{array}$ \\
\hline 12 & & $\begin{array}{l}\text { How do you listen to music?... (multiple choice. Free text option also } \\
\text { available) }\end{array}$ \\
\hline 13 & & $\begin{array}{l}\text { Which instruments do you play?... (multiple choice of instruments, } \\
\text { plus } 5 \text {-point Likert scale from "never" to "at a high standard". Free } \\
\text { text option also available) }\end{array}$ \\
\hline 14 & & Do you like to sing?... (multiple choice) \\
\hline 15 & $\begin{array}{l}\text { Co-design of } \\
\text { music } \\
\text { workshops }\end{array}$ & $\begin{array}{l}\text { Which of the following music workshop activities would interest you } \\
\text { the most?... (multiple choice of activities, plus 3-point Likert scale "not } \\
\text { interested", "a little interested", "really interested") }\end{array}$ \\
\hline 16 & & $\begin{array}{l}\text { Do you have other suggestions for music activities that are planned } \\
\text { for next year? (free text) }\end{array}$ \\
\hline 17 & & $\begin{array}{l}\text { What would be your main reason to come to the music workshops?... } \\
\text { (multiple choice, plus 3-point Likert scale "not important", "a little } \\
\text { important", "really important". Free text option also available) }\end{array}$ \\
\hline 18 & & $\begin{array}{l}\text { How many people would you be comfortable with in each } \\
\text { workshop?... (multiple choice) }\end{array}$ \\
\hline 19 & & $\begin{array}{l}\text { Should everyone in the group be on the autism spectrum (autistic)?... } \\
\text { (multiple choice. Free text option also available) }\end{array}$ \\
\hline 20 & & $\begin{array}{l}\text { What would help you to participate in the music activities?... } \\
\text { (multiple choice) }\end{array}$ \\
\hline 21 & & Is there anything else that we should do to support you? (free text) \\
\hline 22 & & Do you have any more advice for our workshop leaders? (free text) \\
\hline
\end{tabular}

\section{Appendix 2}

Follow-up structured interview questions

\begin{tabular}{ll}
\hline $\begin{array}{l}\text { Question } \\
\text { number }\end{array}$ & Question \\
\hline 1 & Tell us a little about how you use music in your life? \\
2 & $\begin{array}{l}\text { We are planning to run music workshops for small groups of young people. In the } \\
\text { survey, we asked about what music activities would interest you the most. Can you tell } \\
\text { us more about music activities you are interested in, and why? }\end{array}$ \\
& $\begin{array}{l}\text { In the survey, we asked what your main reason for coming to the music workshops } \\
\text { would be. What is your main reason to come to the music workshops? Why is this most } \\
\text { important to you? }\end{array}$ \\
& $\begin{array}{l}\text { We really want to know how to make these workshops autism friendly. What makes it } \\
\text { easier for you to participate in group music activities? }\end{array}$ \\
& $\begin{array}{l}\text { The workshops will have a group leader who is a musician. Do you have any advice for } \\
\text { them? }\end{array}$
\end{tabular}




\section{References}

Allen, R., Hill, E., \& Heaton, P. (2009). The subjective experience of music in autism spectrum disorder. Annals of the New York Academy of Sciences, 1169, 326-331. https://doi.org/10.1111/j.1749$\underline{6632.2009 .04772 . x}$

American Psychiatric Association. (2013). Diagnostic and Statistical Manual of Mental Disorders - DSM-5 (5th ed.). American Psychiatric Publishing.

Australian Institute of Health and Welfare. (2017). Autism in Australia. Retrieved from https://www.aihw.gov.au/reports/disability/autism-in-australia

Autism Spectrum Australia. (2018). Autism prevalence rate up by an estimated 40\% to 1 in 70 people [Press release]. Retrieved from https://www.autismspectrum.org.au/news/autism-prevalence-rate-up-byan-estimated-40-to-1-in-70-people-11-07-2018

Burnard, P., \& Dragovic, T. (2015). Collaborative creativity in instrumental group music learning as a site for enhancing pupil wellbeing. Cambridge Journal of Education, 45(3), 371-392. https://doi.org/10.1080/0305764X.2014.934204

Cage, E., \& Troxell-Whitman, Z. (2019). Understanding the reasons, contexts and costs of camouflaging for autistic adults. Journal of Autism and Developmental Disorders, 49(5), 1899-1911. https://doi.org/10.1007/s10803-018-03878-x

Campbell, F. K. (2009). Contours of Ableism: The Production of Disability and Abledness. Palgrave Macmillan.

Carpente, J. A. (2017). Investigating the effectiveness of a Developmental, Individual Difference, Relationship-Based (DIR) improvisational music therapy program on social communication for children with autism spectrum disorder. Music Therapy Perspectives, 35(2), 160-174. https://doi.org/10.1093/mtp/miw013

Chan, T. (2015). I Can [Poem]. Retrieved from https://timchanblog.wixsite.com/mylifewithautism

Curtis, S. L., \& Mercado, C. S. (2004). Community music therapy for citizens with developmental disabilities. Voices: A World Forum for Music Therapy, 4(3). Retrieved from https://voices.no/index.php/voices/article/view/1624/1384

De La Vega, D., Giner, L., \& Courtet, P. (2018). Suicidality in subjects with anxiety or obsessivecompulsive and related disorders: Recent advances. Current Psychiatry Reports, 20(4), 26. https://doi.org/10.1007/s11920-018-0885-z

den Houting, J. (2019). Neurodiversity: An insider's perspective. Autism, 23(2), 271-273. https://doi.org/10.1177/1362361318820762

Ee, D., Hwang, Y. I., Reppermund, S., Srasuebkul, P., Trollor, J. N., Foley, K.-R., \& Arnold, S. R. (2019). Loneliness in adults on the autism spectrum. Autism in Adulthood, 1(3), 182-193. https://doi.org/10.1089/aut.2018.0038

Geretsegger, M., Elefant, C., Mössler, K., \& Gold, C. (2014). Music therapy for people with autism spectrum disorder. Cochrane Database of Systematic Reviews, 2014(6), CD004381. https://doi.org/10.1002/14651858.CD004381.pub3

Gillespie-Lynch, K., Brooks, P. J., Someki, F., Obeid, R., Shane-Simpson, C., Kapp, S. K., Daou, N., \& Smith, D. S. (2015). Changing college students' conceptions of autism: An online training to increase knowledge and decrease stigma. Journal of Autism and Developmental Disorders, 45(8), 2553-2566. https://doi.org/10.1007/s10803-015-2422-9

Greenhalgh, T., Hinton, L., Finlay, T., Macfarlane, A., Fahy, N., Clyde, B., \& Chant, A. (2019). Frameworks for supporting patient and public involvement in research: Systematic review and codesign pilot. Health Expectations, 22(4), 785-801. https://doi.org/10.1111/hex.12888

Hand, B. N., Benevides, T. W., \& Carretta, H. J. (2019). Suicidal ideation and self-inflicted injury in Medicare enrolled autistic adults with and without co-occurring intellectual disability. Journal of Autism and Developmental Disorders, 1-7. https://doi.org/10.1007/s10803-019-04345-x

Heaton, P. (2003). Pitch memory, labelling and disembedding in autism. Journal of Child Psychology and Psychiatry, 44(4), 543-551. https://doi.org/10.1111/1469-7610.00143

Hedley, D., Uljarević, M., Wilmot, M., Richdale, A., \& Dissanayake, C. (2018). Understanding depression and thoughts of self-harm in autism: A potential mechanism involving loneliness. Research in Autism Spectrum Disorders, 46, 1-7. https://doi.org/10.1016/j.rasd.2017.11.003 
Hillier, A., Greher, G., Poto, N., \& Dougherty, M. (2012). Positive outcomes following participation in a music intervention for adolescents and young adults on the autism spectrum. Psychology of Music, 40(2), 201-215. https://doi.org/10.1177/0305735610386837

Hirvikoski, T., Mittendorfer-Rutz, E., Boman, M., Larsson, H., Lichtenstein, P., \& Bölte, S. (2016). Premature mortality in autism spectrum disorder. The British Journal of Psychiatry, 208(3), $232-238$. https://doi.org/10.1192/bjp.bp.114.160192

Hull, L., Petrides, K., Allison, C., Smith, P., Baron-Cohen, S., Lai, M. C., \& Mandy, W. (2017). "Putting on my best normal": Social camouflaging in adults with autism spectrum conditions. Journal of Autism and Developmental Disorders, 47(8), 2519-2534. https://doi.org/10.1007/s10803-017-3166-5

Jones, S., Akram, M., Murphy, N., Myers, P., \& Vickers, N. (2018). Community attitudes \& behaviours towards autism; and experiences of autistic people and their families: General awareness, knowledge and understanding of autism and social isolation. AMAZE. Retrieved from http://www.onethingforautism.com.au/wp-content/uploads/2018/05/Autism-research-reportGeneral-awareness-knowledge-and-understanding-of-autism-and-social-isolation-1.pdf

Kim, J., Wigram, T., \& Gold, C. (2008). The effects of improvisational music therapy on joint attention behaviours in autistic children: a randomized controlled study. Journal of Autism E Developmental Disorders, 38, 1758-1766. https://doi.org/10.1007/s10803-008-0566-6

Krause, A. E., North, A. C., \& Davidson, J. W. (2019). Using self-determination theory to examine musical participation and well-being. Frontiers in Psychology, 10, 405. https://doi.org/10.3389/fpsyg.2019.00405

Kurchak, S. (2018). I'm autistic. I just turned 36 - The average age when people like me die. Retrieved from https://www.vox.com/first-person/2018/2/19/17017976/autism-average-age-death-36-stress

Lasgaard, M., Nielsen, A., Eriksen, M. E., \& Goossens, L. (2010). Loneliness and social support in adolescent boys with autism spectrum disorders. Journal of Autism and Developmental Disorders, 40(2), 218-226. https://doi.org/10.1007/s10803-009-0851-z

Locock, L., \& Boaz, A. (2019). Drawing straight lines along blurred boundaries: Qualitative research, patient and public involvement in medical research, co-production and co-design. Evidence E Policy: A Journal of Research, Debate and Practice, 15(3), 409-421. https://doi.org/10.1332/174426419X15552999451313

Malloch, S. N. (1999). Mothers and infants and communicative musicality. Musicae scientiae, 3(1_suppl), 29-57. https://doi.org/10.1177/10298649000030S104

Malloch, S. N., \& Trevarthen, C. (2018). The human nature of music. Frontiers in Psychology, 9, 1680. https://doi.org/10.3389/fpsyg.2018.01680

McFerran, K. S. (2020). Adolescents and Music Therapy: Contextualized Recommendations for Research and Practice. Music Therapy Perspectives, 38(1), 80-88. https://doi.org/10.1093/mtp/miz014

Milton, D. E. (2012). On the ontological status of autism: The "double empathy problem". Disability $\mathcal{E}$ Society, 27(6), 883-887. https://doi.org/10.1080/09687599.2012.710008

Molnar-Szakacs, I., Wang, M. J., Laugeson, E. A., Overy, K., Wu, W.-L., \& Piggot, J. (2009). Autism, emotion recognition and the mirror neuron system: The case of music. McGill Journal of Medicine, 12(2), 87. Retrieved from https://www.ncbi.nlm.nih.gov/pmc/articles/PMC2997252/

Morie, K. P., Jackson, S., Potenza, M. N., \& Dritschel, B. (2019). Mood disorders in high-functioning autism: The importance of alexithymia and emotional regulation. Journal of Autism and Developmental Disorders, 49(7), 2935-2945. https://doi.org/10.1007/s10803-019-04020-1

Mottron, L. (2017). Should we change targets and methods of early intervention in autism, in favor of a strengths-based education? European Child E Adolescent Psychiatry, 26(7), 815-825. https://doi.org/10.1007/s00787-017-0955-5

National Health and Medical Research Council. (2016). Statement on Consumer and Community Involvement in Health and Medical Research. Retrieved from https://www.nhmrc.gov.au/aboutus/publications/statement-consumer-and-community-involvement-health-and-medical-research

North, A. C., Hargreaves, D. J., \& O'Neill, S. A. (2000). The importance of music to adolescents. British Journal of Educational Psychology, 70(2), 255-272. https://doi.org/10.1348/000709900158083

Office of Civilian Human Resources. (2016). Convention on the rights of persons with disabilities. Retrieved from http://www.un.org/disabilities/documents/convention/convoptprot-e.pdf 
Oliver, M. (1983). Social work with disabled people. Macmillan.

Oliver, M. (2013). The social model of disability: Thirty years on. Disability $\mathcal{E}$ Society, 28(7), 1024-1026. https://doi.org/10.1080/09687599.2013.818773

Osborne, S. P., Radnor, Z., \& Strokosch, K. (2016). Co-production and the co-creation of value in public services: A suitable case for treatment? Public Management Review, 18(5), 639-653. https://doi.org/10.1080/14719037.2015.1111927

Parsons, M., Fisher, K., \& Nalau, J. (2016). Alternative approaches to co-design: Insights from indigenous/academic research collaborations. Current Opinion in Environmental Sustainability, 20, 99105. https://doi.org/10.1016/j.cosust.2016.07.001

Peretz, I. (2019). How music sculpts our brain: Odile Jacob.

Rideout, V. J., Foehr, U. G., \& Roberts, D. F. (2010). Generation M2: Media in the Lives of 8-to 18-Year-Olds. Retrieved from https://files.eric.ed.gov/fulltext/ED527859.pdf

Roginsky, E., \& Elefant, C. (2020). Silent sounding: Communicability, musicality, and the use of music with nonspeaking individuals with cerebral palsies and multiple disabilities. Nordic Journal of Music Therapy, 1-18. https://doi.org/10.1080/08098131.2020.1810744

Runswick-Cole, K. (2014). 'Us' and 'them': The limits and possibilities of a "politics of neurodiversity" in neoliberal times. Disability \& Society, 29(7), 1117-1129. https://doi.org/10.1080/09687599.2014.910107

Sasson, N. J., Faso, D. J., Nugent, J., Lovell, S., Kennedy, D. P., \& Grossman, R. B. (2017). Neurotypical peers are less willing to interact with those with autism based on thin slice judgments. Scientific Reports, 7, 1-10. https://doi.org/10.1038/srep40700

Scott-Barrett, J., Cebula, K., \& Florian, L. (2019). Listening to young people with autism: Learning from researcher experiences. International Journal of Research E Method in Education, 42(2), 163-184. https://doi.org/10.1080/1743727X.2018.1462791

Shiloh, C., \& LaGasse, A. B. (2014). Sensory friendly concerts: A community music therapy initiative to promote neurodiversity. International Journal of Community Music, 7(1), 113-128. https://doi.org/10.1386/ijcm.7.1.113 1

Singer, J. (1999). Why can't you be normal for once in your life? From a problem with no name to the emergence of a new category of difference. In M. Corker (Ed.), Disability discourse (pp. 59-67). Open Press University.

Singer, J. (2016). NeuroDiversity: The birth of an idea. Amazon Digital Services.

Thompson, G. (2017). Long-term perspectives of family quality of life following music therapy with young children on the autism spectrum: A phenomenological study. Journal of Music Therapy, 54(4), 432-459. https://doi.org/10.1093/jmt/thx013

Thompson, G., McFerran, K., \& Gold, C. (2013). Family-centred music therapy to promote social engagement in young children with severe autism spectrum disorder: A randomised controlled study. Child: Care, Health \& Development, 40(6), 840-852. https://doi.org/10.1111/cch.12121

Tisdall, E. K. M. (2012). The challenge and challenging of childhood studies? Learning from disability studies and research with disabled children. Children $\mathcal{E}$ Society, 26(3), 181-191.

https://doi.org/10.1111/j.1099-0860.2012.00431.x

Uljarević, M., Hedley, D., \& Cai, R. Y. (in press). Anxiety and depression in Autism Spectrum Disorder. In F. Volkmar (Ed.), Encyclopedia of Autism (2 ${ }^{\text {nd }}$ ed.). Springer.

Uljarević, M., Hedley, D., Rose-Foley, K., Magiati, I., Cai, R. Y., Dissanayake, C., Richdale, A., \& Trollor, J. (2019). Anxiety and depression from adolescence to old age in autism spectrum disorder. Journal of Autism and Developmental Disorders, 50(9), 3155-3165. https://doi.org/10.1007/s10803-019-04084-z

Weiss, J. A., Riosa, P. B., Mazefsky, C. A., \& Beaumont, R. (2017). Emotion regulation in autism spectrum disorder. In C. A. Essau, S. LeBlanc, \& T. H. Ollendick (Eds.), Emotion regulation and psychopathology in children and adolescents (pp. 235-258): Oxford University Press.

Wilson, G. B., \& MacDonald, R. A. R. (2019). The social impact of musical engagement for young adults with learning difficulties: A qualitative study. Frontiers in Psychology, 10, 1300. https://doi.org/10.3389/fpsyg.2019.01300

Wright, P. R., \& Pascoe, R. (2015). Eudaimonia and creativity: The art of human flourishing. Cambridge Journal of Education, 45(3), 295-306. https://doi.org/10.1080/0305764X.2013.855172 
Young, L. (2020). Finding our voices, singing our truths: Examining how quality of life domains manifested in a singing group for autistic adults. Voices: A World Forum for Music Therapy, 20(2). https://doi.org/10.15845/voices.v20i2.2554 